AperTO - Archivio Istituzionale Open Access dell'Università di Torino

\title{
Big data in oncologic imaging
}

\section{This is the author's manuscript}

Original Citation:

Availability:

This version is available http://hdl.handle.net/2318/1603194

since 2016-10-17T15:02:33Z

Published version:

DOI:10.1007/s11547-016-0687-5

Terms of use:

Open Access

Anyone can freely access the full text of works made available as "Open Access". Works made available under a Creative Commons license can be used according to the terms and conditions of said license. Use of all other works requires consent of the right holder (author or publisher) if not exempted from copyright protection by the applicable law. 
Dear Author,

Here are the proofs of your article.

- You can submit your corrections online, via e-mail or by fax.

- For online submission please insert your corrections in the online correction form. Always indicate the line number to which the correction refers.

- You can also insert your corrections in the proof PDF and email the annotated PDF.

- For fax submission, please ensure that your corrections are clearly legible. Use a fine black pen and write the correction in the margin, not too close to the edge of the page.

- Remember to note the journal title, article number, and your name when sending your response via e-mail or fax.

- Check the metadata sheet to make sure that the header information, especially author names and the corresponding affiliations are correctly shown.

- Check the questions that may have arisen during copy editing and insert your answers/ corrections.

- Check that the text is complete and that all figures, tables and their legends are included. Also check the accuracy of special characters, equations, and electronic supplementary material if applicable. If necessary refer to the Edited manuscript.

- The publication of inaccurate data such as dosages and units can have serious consequences. Please take particular care that all such details are correct.

- Please do not make changes that involve only matters of style. We have generally introduced forms that follow the journal's style.

Substantial changes in content, e.g., new results, corrected values, title and authorship are not allowed without the approval of the responsible editor. In such a case, please contact the Editorial Office and return his/her consent together with the proof.

- If we do not receive your corrections within $\mathbf{4 8}$ hours, we will send you a reminder.

- Your article will be published Online First approximately one week after receipt of your corrected proofs. This is the official first publication citable with the DOI. Further changes are, therefore, not possible.

- The printed version will follow in a forthcoming issue.

\section{Please note}

After online publication, subscribers (personal/institutional) to this journal will have access to the complete article via the DOI using the URL: http://dx.doi.org/[DOI].

If you would like to know when your article has been published online, take advantage of our free alert service. For registration and further information go to: http://www.link.springer.com.

Due to the electronic nature of the procedure, the manuscript and the original figures will only be returned to you on special request. When you return your corrections, please inform us if you would like to have these documents returned. 


\section{Metadata of the article that will be visualized in OnlineFirst}

\begin{tabular}{|c|c|c|}
\hline ArticleTitle & \multicolumn{2}{|c|}{ Big data in oncologic imaging } \\
\hline \multicolumn{3}{|l|}{ Article Sub-Title } \\
\hline Article CopyRight & \multicolumn{2}{|c|}{$\begin{array}{l}\text { Italian Society of Medical Radiology } \\
\text { (This will be the copyright line in the final PDF) }\end{array}$} \\
\hline Journal Name & \multicolumn{2}{|c|}{ La radiologia medica } \\
\hline \multirow[t]{8}{*}{ Corresponding Author } & Family Name & Mazzetti \\
\hline & Given Name & Simone \\
\hline & Suffix & \\
\hline & Division & Department of Radiology \\
\hline & Organization & Candiolo Cancer Institute-FPO, IRCCS \\
\hline & Email & simone.mazzetti@ircc.it \\
\hline & URL & \\
\hline & ORCID & \\
\hline \multirow{9}{*}{ Author } & Family Name & Regge \\
\hline & Particle & \\
\hline & Given Name & Daniele \\
\hline & Suffix & \\
\hline & Division & Department of Surgical Sciences \\
\hline & Fax & \\
\hline & Email & \\
\hline & URL & \\
\hline & ORCID & \\
\hline \multirow[t]{8}{*}{ Author } & Family Name & Giannini \\
\hline & Particle & \\
\hline & Given Name & Valentina \\
\hline & Suffix & \\
\hline & Division & Department of Radiology \\
\hline & Organization & Candiolo Cancer Institute-FPO, IRCCS \\
\hline & Address & Strada Provinciale 142, km 3.95, Candiolo, Turin, 10060, Italy \\
\hline & Phone & \\
\hline
\end{tabular}


Fax

Email

URL

ORCID

\begin{tabular}{|c|c|c|}
\hline \multirow[t]{12}{*}{ Author } & Family Name & Bracco \\
\hline & Particle & \\
\hline & Given Name & Christian \\
\hline & Suffix & \\
\hline & Division & Department of Medical Physics \\
\hline & Organization & Candiolo Cancer Institute-FPO, IRCCS \\
\hline & Address & Strada Provinciale 142, km 3.95, Candiolo, Turin, 10060, Italy \\
\hline & Phone & \\
\hline & Fax & \\
\hline & Email & \\
\hline & URL & \\
\hline & ORCID & \\
\hline \multirow[t]{12}{*}{ Author } & Family Name & Stasi \\
\hline & Particle & \\
\hline & Given Name & Michele \\
\hline & Suffix & \\
\hline & Division & Department of Medical Physics \\
\hline & Organization & Candiolo Cancer Institute-FPO, IRCCS \\
\hline & Address & Strada Provinciale 142, km 3.95, Candiolo, Turin, 10060, Italy \\
\hline & Phone & \\
\hline & Fax & \\
\hline & Email & \\
\hline & URL & \\
\hline & ORCID & \\
\hline
\end{tabular}

Received

14 June 2016

Schedule Revised

Accepted

29 August 2016

Abstract Cancer is a complex disease and unfortunately understanding how the components of the cancer system work does not help understand the behavior of the system as a whole. In the words of the Greek philosopher Aristotle "the whole is greater than the sum of parts." To date, thanks to improved information technology infrastructures, it is possible to store data from each single cancer patient, including clinical data, medical images, laboratory tests, and pathological and genomic information. Indeed, medical archive storage constitutes approximately one-third of total global storage demand and a large part of the data are in the form of medical images. The opportunity is now to draw insight on the whole to the benefit of each individual patient. In the oncologic patient, big data analysis is at the beginning but several useful applications can be envisaged including development of imaging biomarkers to predict disease outcome, assessing the risk of X-ray dose exposure or of renal damage following the administration of contrast agents, and tracking and optimizing patient workflow. The aim of this review is to present current evidence of how big data derived from medical images may impact on the diagnostic pathway of the oncologic patient.

Keywords (separated by '-') Oncologic imaging - Big data - Quantitative imaging biomarkers - X-ray dose - Renal damage - Imaging databases

Footnote Information 


\section{Big data in oncologic imaging}

3 Daniele Regge ${ }^{1,2} \cdot$ Simone Mazzetti $^{2} \cdot$ Valentina Giannini $^{2} \cdot$ Christian Bracco $^{3} \cdot$
4 Michele Stasi $^{3}$

5 Received: 14 June 2016 / Accepted: 29 August 2016

6 C) Italian Society of Medical Radiology 2016
7 Abstract Cancer is a complex disease and unfortunately
Simone Mazzetti

simone.mazzetti@ircc.it

1 Department of Surgical Sciences, University of Torino, A.O.U. Città della Salute e della Scienza, via Genova 3, 10126 Turin, Italy

2 Department of Radiology, Candiolo Cancer InstituteFPO, IRCCS, Strada Provinciale 142, km 3.95, Candiolo, 10060 Turin, Italy

3 Department of Medical Physics, Candiolo Cancer InstituteFPO, IRCCS, Strada Provinciale 142, km 3.95, Candiolo, 10060 Turin, Italy
Keywords Oncologic imaging $\cdot$ Big data $\cdot$ Quantitative imaging biomarkers $\cdot \mathrm{X}$-ray dose $\cdot$ Renal damage $\cdot$ Imaging databases

\section{Introduction}

Big Data initiatives are aimed at drawing inferences from large datasets that are not derived from carefully controlled information [1]. In medicine, the basic idea behind using big data is to learn new knowledge from every patient we have ever treated and apply this knowledge to the next patient [2]. This concept will give future generations the opportunity to bring into existence a "fast learning health system" to the benefit of each individual patient. In the era of precision medicine, this evolutionary concept may lead to a comprehensive and individual approach to treatment [3]. In oncology, where information collected from the single patient is extremely variegated, big data analysis could allow definition of specific and efficient diagnostic and therapeutic pathways, improving patient workflow and quality of life. The aim of this review is to collect current evidence and to envisage how in the future big data may impact on the diagnostic pathway of the oncologic patient.

\section{Big data in oncologic imaging: the rationale}

The following key concepts related to big data should be considered when approaching oncologic imaging issues:

1. Opposite to traditional hypothesis-driven cancer research [4], big data research may be launched regardless of whether important questions are identified.
33

34

35

36

37

38

39

40

41

42

43

44

45

46

47

48

49

\begin{tabular}{l|lll|} 
Journal : Large 11547 & Dispatch : 31-8-2016 & Pages : 6 \\
Article No : $\mathbf{6 8 7}$ & $\square$ LE & $\square$ TYPESET \\
MS Code : RAME-D-16-00155 & $\square \quad C P$ & $\square$ DISK \\
\hline
\end{tabular}




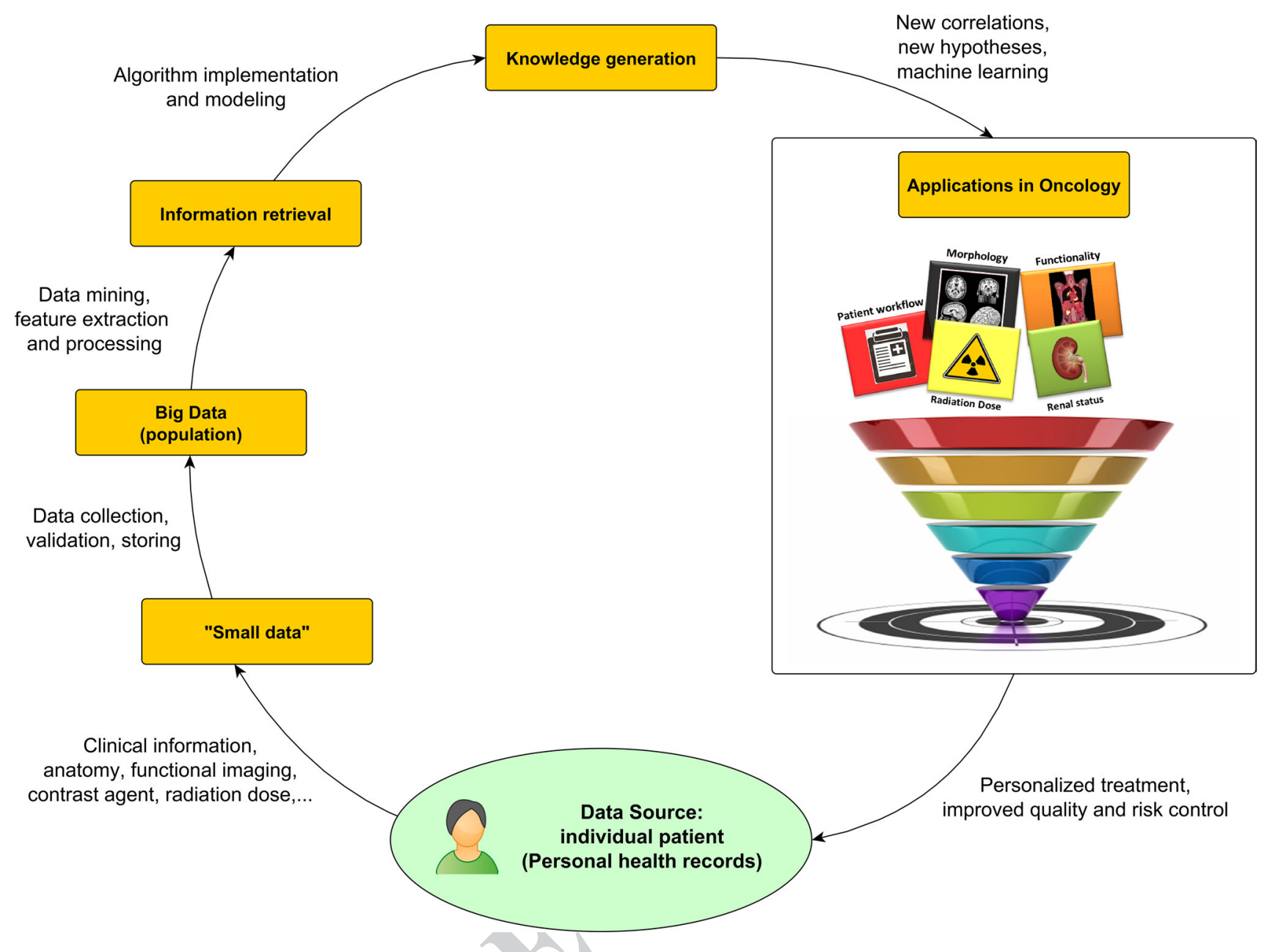

Fig. 1 Circle of medical knowledge in oncology. The individual patient is the source of information and the target of care delivery

2. Big data in health consists in datasets that are too big, too inhomogeneous, and too complex for healthcare providers to process and interpret with existing tools [5].

3. Big data is not about implementing one piece of technology, it also includes data mining and machine learning and offers potential alternative approaches to leveraging large data resources $[6,7]$.

Cancer fits well into these concepts, as it is a complex disease that changes, evolves, and adapts to the surrounding environment. Its evolution could be better understood by collecting information from different sources-e.g., demographic, genetic, imaging, treatment, and outcomesthat could then be processed as big data. In the last two decades, the development of efficient information technology (IT) infrastructures has allowed digitalization and electronic integration of healthcare information [8]. In 2012, AT\&T estimated that the storage requirements for medical archives were increasing by $20-40 \%$ each year, with medical images constituting one-third of total global storage demand $[9,10]$. Today, an average size hospital manages approximately $665 \mathrm{~TB}$ of patient data, corresponding to approximately 140.000 DVDs [11].

Big data has the potential to dramatically reshape cancer care landscape, improving quality and efficiency in every cancer setting [12] (Fig. 1). In the field of oncologic imaging, big data may allow the development of tools for baseline assessment and for quantification of anatomic and functional changes over time. Quantitative imaging biomarkers will contribute to tailoring treatment to each individual patient. Extraction of data from radiation and contrast agent dose registries will allow to explore dose effects on subjects with cumulative X-rays, computed tomography (CT) scans, radiation therapy treatments, or nuclear medicine examinations and minimize contrast-induced nephrotoxicity by stratifying cancer patients into risk categories. Finally, processing of big data could support the development of optimized clinical workflows and in the end increase the management efficiency of comprehensive

\begin{tabular}{|l|ll|} 
Journal : Large 11547 & Dispatch : 31-8-2016 & Pages : $\mathbf{6}$ \\
Article No : $\mathbf{6 8 7}$ & $\square$ LE & $\square$ TYPESET \\
MS Code : RAME-D-16-00155 & $\square \quad$ CP & $\square \quad$ DISK \\
\hline
\end{tabular}


cancer centers and of tertiary health facilities in general [13].

\section{Big data in oncologic imaging: current developments}

Today, most of what we know about cancer comes from a tiny subset of patients, i.e., the $3 \%$ who are enrolled in clinical trials; hence, those data are non-representative of the entire cancer population [14]. The remaining $97 \%$ generate potentially useful information that is lost, due to the fact that data collection is mostly non-structured. In recent years, publicly accessible medical repositories are being implemented with the aim of collecting data from different imaging modalities. The cancer imaging archive (TCIA), for example, provides a public repository of cancer images and related clinical data [15]. The repository was created with the support of the National Cancer Institute with the aim of collecting, curating, and managing a rich collection of oncologic imaging data to enable open-science research. [16]. At present, more than 26 million radiologic images contributed by 28 institutions and several thousand pathology images are stored in this repository that is constantly increasing in size and variety [15]. In this chapter, we will review how the analysis of all this information benefits each individual patient.

\section{Extracting the "dark matter" from medical images}

In medical images, data are usually provided as an orderly set of gray scale pixel values; however, in this form data are not synonymous of information or knowledge. Indeed, of the estimated $80 \%$ of hospital data that are represented by unstructured imaging data [11], very little are currently being used for diagnosis. Eliot Siegel from the University of Maryland compared the data hidden in a clinical image, i.e., data that cannot be directly observed with current technology, as the "dark matter in space" [17]. The main challenge for future generations will be to extract important and meaningful information from this dark matter. Improvements in image analysis will reasonably bridge the gap between the visual content and its numeric representation, which includes encoded color and texture properties of an image, the spatial layout of objects, and geometric shape characteristics of anatomical structures. More and more diagnostic techniques are providing multi-modality imaging, with challenging big data management issues. A magnetic resonance (MR) examination, for example, includes high-resolution morphological images and information on tissue perfusion and diffusion capturing complex in vivo flow patterns; similarly, CT dual-energy acquisitions include information on material decomposition and spectral imaging [18]. Furthermore, combining different imaging modalities at the hardware level (MR/PET, PET/CT) will open up a range of new opportunities for image analysis [5].

Pattern recognition software and tools for high-throughput extraction of quantitative features have been implemented in parallel to the increase in dataset size and information. Conversion of images into mineable data and subsequent analysis for clinical decision support has paved the way to radiomics [1]. Radiomic data typically contain first-, second-, and higher-order statistics that can be combined with other patient data to develop models with improved diagnostic, prognostic, and predictive accuracy.

\section{Diagnostic X-ray dose exposure}

During the past 30 years, radiologic procedures involving ionizing radiation have been increasingly used in clinical routine leading to a dramatic increase in individual patient dose exposure. Today, medical radiation comprises almost $50 \%$ of per capita radiation dose, compared with $15 \%$ in the early 1980s [19]. Individual risk of developing radiation-related cancer from any single imaging procedure is extremely low; however, repeated examinations may lead to a substantial increase in such risk [20]. Unfortunately, epidemiologic literature on low-dose effects of ionizing radiations is limited by statistical power. In the future, the opportunity to exploit large databases will help clarify the relationship between cancer-induced pathologies and lowdose radiation levels $[21,22]$. In particular, the introduction of radiation dose registries could be a valuable tool for patient monitoring and optimization of dose delivery. Collected information should include (1) radiation dose distributions and dose-volume metrics from treatment planning in radiotherapy (i.e., dose-volume histograms, the volume receiving a certain dose, minimum dose to a given volume, mean, maximum, and minimum dose); (2) X-ray doses from radiological imaging (i.e., volumetric $\mathrm{CT}$ dose index, dose-length product, dose-area product); and (3) gammaray and other radioisotopes radiation doses from nuclear medicine imaging and treatment. A radiation dose registry may allow clinicians to compare dose levels to the averages of other national and international centers, in order to successfully implement low-dose protocols. On the side, this $\mathbf{A Q 3}_{5}$ will favor standardization, create higher patient confidence 186 in radiation safety, and offer the opportunity for better quality assessment.

Regulations and guidelines, such as the European directive Euratom 97/43, 2013/59/EURATOM, and the American College of Radiology dose Whitepaper, express the need for facilities to track radiation dose for patient and population, and support the implementation for dose registries. In particular, the European directive 2013/59/

\begin{tabular}{l|lll|} 
Journal : Large 11547 & Dispatch : 31-8-2016 & Pages : 6 \\
Article No : $\mathbf{6 8 7}$ & $\square$ LE & $\square$ TYPESET \\
MS Code : RAME-D-16-00155 & $\square \quad C P$ & $\square$ & DISK \\
\hline
\end{tabular}


EURATOM points out that health authorities will be more pervasive on inspecting the dosimetry applied to patients. Integrating the Healthcare Enterprise (IHE-www.ihe.net) is an initiative of professional societies aimed at collaborating with the industry in order to coordinate standards-based solutions to problems that span multiple vendors systems. The new IHE radiation exposure monitoring (REM) Profile facilitates the collection and distribution of the estimated patient radiation exposure information resulting from imaging procedures and provides an implementation guide for vendors. By following this guide and participating in IHE Connectathon, vendors can release products that will interoperate to provide an exposure monitoring pipeline (http:// www.aapm.org/meetings/amos2/pdf/42-12234-94897-404. pdf).

Some healthcare companies have already developed web-based dose management software to track and analyze patient radiation and iodine exposure across multi-facility, multi-modality, and multi-vendor imaging environments. These systems enable healthcare professionals to monitor radiation exposure and contrast media injection dose to their patients. In addition, these devices allow optimization of acquisition protocols in order to find the right balance between image quality and dose, minimizing the risk of radiation-induced cancers (http://www.dicardiology. com/article/software-help-manage-medical-imaging-radiation-dose). On the technical side, there are several crucial aspects of dose tracking that deserve to be remembered. The first is dose capture: non-DICOM-SR compatible CT scanners store dose information as images rather than in numerical form, requiring an optical character recognition algorithm to capture the data. Second, information has to be associated with the patient to be exportable to dose registries such as the American College of Radiology (ACR) Dose Index Registry (DIR). This database, opened in 2011, represents the most substantial effort to standardize radiation dose across the United States. Information related to dose indices to regional and national values is collected, anonymized, and stored across different care services. In 2013, the registry achieved dose index information on 5.5 million CT examinations across 750 registered facilities [23]. DIR is a data registry that allows facilities to compare their CT dose indices to regional and national values. Institutions are provided with periodic feedback reports comparing their results by body part and exam type to aggregate results (http://www.acr.org/Quality-Safety/ National-Radiology-Data-Registry/Dose-Index-Registry).

\section{Big data and radiation oncology}

Big data repositories include detailed 3-dimensional dosimetric and imaging data, and their changes over time. Of these, the National Radiation Oncology Registry was designed to collect information on cancer care delivery among patients treated with radiation therapy [24, 25]. Predictive models can be applied to the collected treatment variables to assess patient outcome. In a pilot project, prostate cancer was selected as the initial disease site, and information was collected on clinical features, toxicity, and spatial and temporal dose distribution. Thanks to this pilot study, researchers may now identify best strategy options that allow patients to safely choose to do nothing or opt for mild treatments or surgery [26]. In the era of genomics, one may envision leveraging large repositories with detailed radiation therapy data, imaging data, and genomic profiles of tumor and normal tissue samples in order to better understand predictors of tumor control and risk of normal tissue injury, providing radiation oncologists the opportunity to potentially offer personalized dose prescriptions improving tumor control and reducing toxicity [7, 27].

\section{Predicting renal damage}

In recent years, the study of acute kidney injury has been facilitated by the increasing availability of stored demographic and clinical patient data [28, 29]. The Chronic Database of Kidney Diseases (CDKD), for example, is a database system designed to hold personal and laboratory investigatory details of patients with renal disease (http:// www.cdkd.org/). Its goal is to make kidney-related physiological data easily available to the scientific community. CDKD currently contains more than 10,000 public data entries, available upon free registration [30]. Unfortunately, most datasets do not provide standardized information, and do not allow differentiation between acute and chronic disease. This heterogeneity may hinder comparisons and underestimate disease burden, limiting its application in a clinical setting [28].

Collecting information on kidney functional status could be particularly useful in cancer patients. These patients frequently repeat CT examinations for staging or assessment of response to treatment, in which administration of intravenous iodine contrast agent is generally required. It is well known that iodinated contrast agents are associated with an increased risk of contrast-induced nephrotoxicity; the risk is particularly high in patients that have impaired renal function and diabetes [31]. Furthermore, renal failure in oncological patients is often multifactorial and more common than in the general population [32]. The risk of complications from contrast medium administration is compounded by advanced age, dehydration, the number of times CT is repeated, and co-administration of nephrotoxic chemotherapeutic drugs. Thus, identification of factors predicting contrast-induced nephrotoxicity is important to avoid potentially serious complications, related to acute deterioration of kidney function [31].
263

\begin{tabular}{|l|ll|}
\hline Journal : Large 11547 & Dispatch : 31-8-2016 & Pages : $\mathbf{6}$ \\
Article No : $\mathbf{6 8 7}$ & $\square$ LE & $\square$ TYPESET \\
MS Code : RAME-D-16-00155 & $\square \quad$ CP & $\square \quad$ DISK \\
\hline
\end{tabular}




\section{Tracking patient workflow}

Oncological patient management is more and more a complex matter requiring constant monitoring throughout chemotherapy lines, radiation therapy sessions, scheduled follow-up assessments, etc. Thus, information collected from the very first diagnosis to outcome of every single patient is growing fast. To date, most of this information is passively accumulated by hospitals within PACS and RIS facilities. Conversely, in an integrated healthcare system, where interdisciplinary teams of specialists act together, all information should be linked with the aim of optimizing individual patient care, paving the way to truly personalized medicine.

To optimize current oncological workflows, it will be necessary to develop event-tracking systems in which monitoring points based on checklists are implemented. A good system should be able to identify workflow issues and technical errors in every step of patient management, advancing department quality control and improving existing processes or implementing new workflows [33]. Each patient in the processing chain will thus contribute to help clinicians and technicians to detect workflow inefficiencies, as incorrectly transmitted images or information during disease assessment, or delays in scheduled follow-ups. A patient tracking system would also simplify pinpointing the sources of error or mismatching within processes, producing as a result an honest picture of the current events, and enhance the ability to respond in real time. The opportunity at hand using big data is the ability to scan and connect massive repositories with the aim of providing new insights on patient workflow. Correlating clinical data with costs, outcomes, and performances will also support the development of evidence-based guidelines and clinical best practices. In the end, again, all of this will improve patient's access to treatment, reduce therapy side effects, and contribute to improve his quality of life and, on a population scale, allow healthcare systems to save more lives and contain costs.

\section{Conclusions}

The possibility to extract new knowledge from the huge amount of increasingly available unstructured data is crucial for advances in cancer diagnosis and treatment. Indeed, the strength of big data lies in its volume and variety. However, this process is not without challenges as big data analysis also has several intrinsic limitations, which limit its use. First, big data is usually extremely heterogeneous, can be missing, non-interpretable, conflicting, inaccurate, or stored in different locations. Second, it may be beyond human capabilities to analyze. Indeed, the very point of looking to big data is "to identify patterns that create answers to questions you didn't even know to ask" [34]. Finally, big data analysis may breach patient privacy. Therefore, the success of big data in creating healthcare value may require some changes in the current polices, to balance the potential societal benefits of big data approaches and the protection of patients' confidentiality [35].

In conclusion, the benefits of large-scale data mining to the oncologic patient are slowly emerging. Big data initiatives could be instrumental in improving the management and the quality of life of each individual cancer patient based on the results of imaging biomarker analysis or on the implementation of event-tracking systems. On a macroeconomics level, big data could support the implementation of evidence-based guidelines and of quality control measures, in the end reducing system inefficiencies. Because of their intrinsic heterogeneity, it will be very challenging to fully exploit big data.

\section{Compliance with ethical standards}

No funding was received for this work.

Conflict of interest Daniele Regge declares that he has no conflict of interest. Simone Mazzetti declares that he has no conflict of interest. Valentina Giannini declares that she has no conflict of interest. Christian Bracco declares that he has no conflict of interest. Michele Stasi declares that he has no conflict of interest.

Ethical approval This article does not contain any studies with human participants or animals performed by any of the authors.

\section{References}

1. Gillies RJ, Kinahan PE, Hricak H (2016) Radiomics: images are more than pictures, they are data. Radiology 278(2):563-577. doi:10.1148/radiol.2015151169

2. Schneeweiss S (2014) Learning from big health care data. N Engl J Med 370(23):2161-2163. doi:10.1056/NEJMp1401111

3. McGrath S, Ghersi D (2016) Building towards precision medicine: empowering medical professionals for the next revolution. BMC Med Genom 9(1):23. doi:10.1186/s12920-016-0183-8

4. Etheredge LM (2014) Rapid learning: a breakthrough agenda. Health Aff 33(7):1155-1162. doi:10.1377/hlthaff.2014.0043

5. Andreu-Perez J, Poon CC, Merrifield RD et al (2015) Big data for health. IEEE J Biomed Health Inform 19(4):1193-1208. doi:10.1109/JBHI.2015.2450362

6. Berger ML, Doban V (2014) Big data, advanced analytics and the future of comparative effectiveness research. J Comp Eff Res 3(2):167-176. doi:10.2217/cer.14.2

7. Trifiletti DM, Showalter TN (2015) Big data and comparative effectiveness research in radiation oncology: synergy and accelerated discovery. Front Oncol 5:274. doi:10.3389/ fonc. 2015.00274

8. Kansagra AP, Yu JP, Chatterjee AR et al (2016) Big data and the future of radiology informatics. Acad Radiol 23(1):30-42. doi:10.1016/j.acra.2015.10.004

\begin{tabular}{l|lll|} 
Journal : Large 11547 & Dispatch : 31-8-2016 & Pages : 6 \\
Article No : $\mathbf{6 8 7}$ & $\square \quad$ LE & $\square$ TYPESET \\
MS Code : RAME-D-16-00155 & $\square \quad C P$ & $\square$ DISK \\
\hline
\end{tabular}


9. Frost \& Sullivan (2012) Medical imaging in the cloud. AT\&T Intellectual Property

10. Ghasemi Frad N, Mirarab A, Shamsi M (2014) A cloud solution for medical image archive. Int J Curr Life Sci 4(6):2999-3005

11. Byrne E (2013) Scientists save healthcare (but they're not from med school). http://www.forbes.com/sites/netapp/2013/04/17/ healthcare-big-data. Accessed 9 June 2016

12. Dizon DS, Krilov L, Cohen E et al (2016) Clinical cancer advances 2016: annual report on progress against cancer from the american society of clinical oncology. J Clin Oncol 34(9):987-1011. doi:10.1200/JCO.2015.65.8427

13. Rosenstein BS, Capala J, Efstathiou JA et al (2015) How will big data improve clinical and basic research in radiation therapy? Int J Radiat Oncol Biol Phys. doi:10.1016/j.ijrobp.2015.11.009 [Epub ahead of print]

14. Meyer AM, Basch E (2015) Big data infrastructure for cancer outcomes research: implications for the practicing oncologist. J Oncol Pract 11(3):207-208. doi:10.1200/JOP.2015.004432

15. Kalpathy-Cramer J, Freymann JB, Kirby JS et al (2014) Quantitative imaging network: data sharing and competitive algorithm validation leveraging the cancer imaging archive. Transl Oncol 7(1):147-152

16. Prior FW, Clark K, Commean P et al (2013) TCIA: an information resource to enable open science. Conf Proc IEEE Eng Med Biol Soc 2013:1282-1285. doi:10.1109/EMBC.2013.6609742

17. Ridley EL (2014) Big data in radiology will drive personalized patient care. http://www.auntminnie.com/index.aspx?sec $=$ ser $\& s$ $\mathrm{ub}=\mathrm{def} \& \mathrm{pag}=\mathrm{dis} \& \mathrm{ItemID}=108619$. Accessed 9 June 2016

18. Silva AC, Morse BG, Hara AK et al (2011) Dual-energy (spectral) CT: applications in abdominal imaging. Radiographics 31(4):1031-1050. doi:10.1148/rg.314105159

19. Linet MS, Slovis TL, Miller DL et al (2012) Cancer risks associated with external radiation from diagnostic imaging procedures. CA Cancer J Clin 62(2):75-100. doi:10.3322/caac.21132

20. National Council on Radiation Protection and Measurements (2009) ionizing radiation exposure of the population of the United States. NCRP Report No. 160. Bethesda, MD

21. Dauer LT, Brooks AL, Hoel DG et al (2010) Review and evaluation of updated research on the health effects associated with low-dose ionising radiation. Radiat Prot Dosim 140(2):103-136. doi:10.1093/rpd/ncq141

22. Muirhead CR, O'Hagan JA, Haylock RG et al (2009) Mortality and cancer incidence following occupational radiation exposure: third analysis of the National Registry for Radiation Workers. $\mathrm{Br}$ J Cancer 100(1):206-212. doi:10.1038/sj.bjc.6604825

23. Bhargavan-Chatfield M, Morin RL (2013) The ACR computed tomography dose index registry: the 5 million examination update. J Am Coll Radiol 10(12):980-983. doi:10.1016/j. jacr.2013.08.030

24. Efstathiou JA, Nassif DS, McNutt TR et al (2013) Practice-based evidence to evidence-based practice: building the national radiation oncology registry. J Oncol Pract 9(3):e90-e95. doi:10.1200/ JOP.2013.001003

25. Bekelman JE, Wall T, Nassif D et al (2013) The national radiation oncology registry: approaches to regulatory compliance to promote wide participation. Int $\mathrm{J}$ Radiat Oncol Biol Phys 87(2):S493. doi:10.1016/j.ijrobp.2013.06.1303

26. Deng J (2014) Big data in radiation oncology: challenges and opportunities. Cancer Sci Res Open Access 1(2):1-2

27. Gabriele D, Jereczek-Fossa BA, Krengli M et al (2016) Beyond D'Amico risk classes for predicting recurrence after external beam radiotherapy for prostate cancer: the Candiolo classifier. Radiat Oncol 11:23. doi:10.1186/s13014-016-0599-5

28. Siew ED, Basu RK, Wunsch H et al (2016) Optimizing administrative datasets to examine acute kidney injury in the era of big data: workgroup statement from the 15th ADQI Consensus Conference. Can J Kidney Health Dis 3:12. doi:10.1186/ s40697-016-0098-5

29. Bagshaw SM, Goldstein SL, Ronco C et al (2016) Acute kidney injury in the era of big data: the 15th Consensus Conference of the Acute Dialysis Quality Initiative (ADQI). Can J Kidney Health Dis 3:5. doi:10.1186/s40697-016-0103-Z

30. Singh SK, Malik A, Firoz A et al (2012) CDKD: a clinical database of kidney diseases. BMC Nephrol 13:23. doi:10.1186/1471-2369-13-23

31. Heiken JP (2008) Contrast safety in the cancer patient: preventing contrast-induced nephropathy. Cancer Imaging 8:S124S127. doi:10.1102/1470-7330.2008.9018

32. Humphreys BD, Soiffer RJ, Magee CC (2005) Renal failure associated with cancer and its treatment: an update. J Am Soc Nephrol 16(1):151-161. doi:10.1681/ASN.2004100843

33. Liu C, Yeung AR, Greenwalt J et al (2014) Designing a patient treatment workflow management and analysis system in a department of radiation oncology. Int $\mathrm{J}$ Radiat Oncol Biol Phys 90(1):S746-S747. doi:10.1016/j.ijrobp.2014.05.2169

34. Bollier D (2010) The premise and peril of big data. Communications and society program. https://www.emc.com/collateral/analyst-reports/10334-ar-promise-peril-of-big-data.pdf. Accessed 9 June 2016

35. Roski J, Bo-Linn GW, Andrews TA (2014) Creating value in health care through big data: opportunities and policy implications. Health Aff 33(7):1115-1122. doi:10.1377/ hlthaff.2014.0147

\begin{tabular}{llll|} 
Journal : Large 11547 & Dispatch : 31-8-2016 & Pages : 6 \\
Article No : $\mathbf{6 8 7}$ & $\square$ LE & $\square$ TYPESET \\
MS Code : RAME-D-16-00155 & $\square \quad C P$ & $\square$ DISK \\
\hline
\end{tabular}




\begin{tabular}{|ll|}
\hline Journal: & $\mathbf{1 1 5 4 7}$ \\
Article: & $\mathbf{6 8 7}$ \\
\hline
\end{tabular}

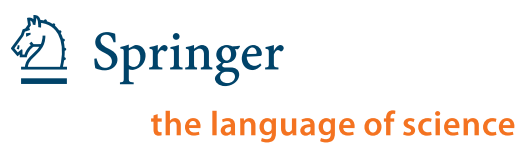

\section{Author Query Form}

\section{Please ensure you fill out your response to the queries raised below and return this form along with your corrections}

Dear Author

During the process of typesetting your article, the following queries have arisen. Please check your typeset proof carefully against the queries listed below and mark the necessary changes either directly on the proof/online grid or in the 'Author's response' area provided below

\begin{tabular}{|l|l|l|}
\hline Query & Details Required & Author's Response \\
\hline AQ1 & $\begin{array}{l}\text { Please check and confirm whether the affliations are processed correctly. Please amend } \\
\text { if necessary. }\end{array}$ & \\
\hline AQ2 & Please confirm the section headings are correctly identified. & \\
\hline AQ3 & $\begin{array}{l}\text { Please check the given sentence 'On the side, this will favor standardization...' for } \\
\text { clarity and amend if necessary]. }\end{array}$ & \\
\hline AQ4 & Please provide complete detailas for Ref. [9]. & \\
\hline
\end{tabular}

